Wright State University

CORE Scholar

8-1-1993

\title{
Semi-insulating Nature of Gas Source Molecular Beam Epitaxial InGaP Grown at Very Low Temperatures
}

David C. Look

Wright State University - Main Campus, david.look@wright.edu

Y. He

J. Ramdani

N. Elmasry

S. M. Bedair

Follow this and additional works at: https://corescholar.libraries.wright.edu/physics

Part of the Physics Commons

\section{Repository Citation}

Look, D. C., He, Y., Ramdani, J., Elmasry, N., \& Bedair, S. M. (1993). Semi-insulating Nature of Gas Source Molecular Beam Epitaxial InGaP Grown at Very Low Temperatures. Applied Physics Letters, 63 (9), 1231-1233.

https://corescholar.libraries.wright.edu/physics/46

This Article is brought to you for free and open access by the Physics at CORE Scholar. It has been accepted for inclusion in Physics Faculty Publications by an authorized administrator of CORE Scholar. For more information, please contact library-corescholar@wright.edu. 


\title{
Semi-insulating nature of gas source molecular beam epitaxial InGaP grown at very low temperatures
}

\author{
D. C. Look \\ University Research Center, Wright State University, Dayton, Ohio 45435 \\ Y. He, J. Ramdani, N. El-Masry, and S. M. Bedair \\ Department of Electrical and Computer Engineering, North Carolina State University, Raleigh, \\ North Carolina 27695
}

(Received 16 February 1993; accepted for publication 16 June 1993)

\begin{abstract}
$\mathrm{In}_{x} \mathrm{Ga}_{1-x} \mathrm{P}$ lattice matched to GaAs $(x=0.51)$ has proven to be useful in many device applications. Here we show that undoped, semi-insulating InGaP is possible by growing with gas source molecular beam epitaxy at very low temperatures, $150-250^{\circ} \mathrm{C}$. The material grown at about $200{ }^{\circ} \mathrm{C}$ is $n$-type with a $296-\mathrm{K}$ resistivity of $9 \times 10^{5} \Omega \mathrm{cm}$, a mobility of $120 \mathrm{~cm}^{2} / \mathrm{V} \mathrm{s}$, and a donor activity energy of $0.48 \mathrm{eV}$. When annealed at $600^{\circ} \mathrm{C}$ for $1 \mathrm{~h}$, the resistivity increases to greater than $10^{9} \Omega \mathrm{cm}$ and the resistivity activation energy to $0.8 \mathrm{eV}$.
\end{abstract}

$\operatorname{In}_{0.51} \mathrm{Ga}_{0.49} \mathrm{P}$ (hereafter simply called InGaP) is lattice matched to GaAs and thus epitaxial layers and devices made from this material are compatible with semiinsulating (SI) GaAs substrates and the relatively mature GaAs technology. With both $n$ - and $p$-type doping available, and a relatively high band gap of $1.9 \mathrm{eV}$, many device applications have been proposed and are being implemented. For example, a high valence-band discontinuity with GaAs and a low Be diffusion coefficient make InGaP an attractive emitter material for $\mathrm{InGaP} / \mathrm{GaAs} / \mathrm{GaAs}$ heterojunction bipolar transistors. ${ }^{1}$ Furthermore, its good passivation properties are useful in this application and others. However, a common problem in many semiconductor materials is the lack of a stable, semi-insulating form, especially one that can be grown by epitaxial methods. For example, epitaxial GaAs and InP can be made semiinsulating by doping with $\mathrm{Fe}$ or $\mathrm{Cr}$, but these elements tend to diffuse at high temperatures. ${ }^{2}$ Here we show that InGaP grown by gas-source molecular beam epitaxy (GSMBE) at a low temperature (LT) is semi-insulating, and that hightemperature annealing produces an even higher resistivity. This property, along with a short recombination time, suggests possible fast photoconductive switch and metalinsulator field-effect transistor (MISFET) applications.

The samples used in this work were grown in a Riber 32RD GSMBE system. Semi-insulating (SI) liquid encapsulated Czochralski (LEC) GaAs (100) substrates were used and the substrates were mounted on a Mo block with high purity indium solder. Before growth, the substrate was heated to $630^{\circ} \mathrm{C}$ for about $10 \mathrm{~min}$ for desorption of the oxides on the substrate surface. Solid $\mathrm{Ga}$ and In sources and $100 \%$ pure $\mathrm{PH}_{3}$ thermally cracked at $900^{\circ} \mathrm{C}$ were used to grow the InGaP layers to thicknesses of 1-2 $\mu \mathrm{m}$ at substrate temperatures of about $150-250{ }^{\circ} \mathrm{C}$. (However, only the $200^{\circ} \mathrm{C}$ sample will be discussed in detail here.) The substrate holder was rotated throughout the growth process to assure uniform deposition. The growth rate of the epilayer was $0.5 \mu \mathrm{m} / \mathrm{h}$. The growth chamber pressure was stabilized at mid- $10^{-5}$ Torr during growth using a turbomolecular pump. The in situ reflection high-energy electron diffraction (RHEED) showed a streaky pattern indicating crystalline growth of LT grown films.

Double-crystal $x$-ray diffraction (DCXRD) showed that the LT InGaP films had about $47 \%$ In, slightly below the lattice-matched composition. In order to compare the structural properties of the LT InGaP film with those of a "normal" InGaP film grown at a high temperature of about $480^{\circ} \mathrm{C}$ (hereafter referred to as HT InGaP) at the same In composition, the structure shown in Fig. 1 was grown. DCXRD peaks for (400) reflection planes, shown in Fig. 2(a), were observed for the substrate, LT InGaP, and $\mathrm{HT}$ InGaP films, respectively. Upon annealing at $600^{\circ} \mathrm{C}$ for $1 \mathrm{~h}$, the LT InGaP (400) reflection was the only one shifted, as shown in Fig. 2(b), thus confirming it is that of the LT InGaP film. The observation that annealing did not have any effect on the HT InGaP peak position was expected. The angular separation between the LT InGaP and the HT InGaP reflections was 70 arcsec before annealing and 50 arcsec after annealing. The fact that the LT InGaP peak is situated on the left-hand side of the HT InGaP peak implies that the LT InGaP film has a slightly larger lattice parameter than that of the HT InGaP film. Lattice expansion in the LT InGaP film can be explained by the presence of excess phosphorus incorporated into the LT film due to nonstoichiometric growth. After annealing, the LT InGaP peak shift indicates a decrease in lattice parameter of the I,T InGaP films, as was also reported for the LT growth of $\mathrm{GaAs}^{3}$ and $\mathrm{GaP} .{ }^{4}$ Further details on the structural characterization of LT InGaP will be reported elsewhere. ${ }^{5}$

\begin{tabular}{lll}
\hline LT InGaP & $2000^{\circ} \mathrm{C}$ & $\mathrm{I \mu m}$ \\
\hline HT InGaP & $480^{\circ} \mathrm{C}$ & $1 \mu \mathrm{m}$ \\
\hline GaAs buffer & $550^{\circ} \mathrm{C}$ & $1 \mu \mathrm{m}$ \\
\hline
\end{tabular}

FIG. 1. Schematic of the multilayer sample with a LT InGaP film ( $T$. $\left.=200^{\circ} \mathrm{C}, 1 \mu \mathrm{m}\right)$ grown on top of a HT InGaP film $\left(T_{s}=480^{\circ} \mathrm{C}, 1 \mu \mathrm{m}\right)$. 


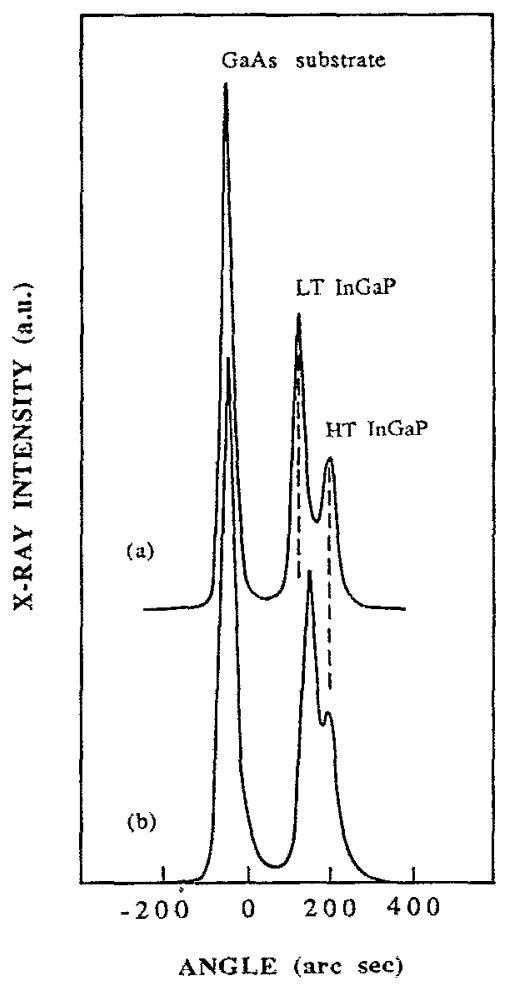

FIG. 2. Double-crystal x-ray diffraction from (400) reflection planes of the sample shown in Fig. 1. (a) Unannealed, the angular separation between the LT InGaP and the HT InGaP reflections is 70 arcsec. (b) Annealed at $600^{\circ} \mathrm{C}$ for $1 \mathrm{~h}$, the angular separalion between the LT InGaP and the $\mathrm{HT}$ InGaP reflections is 50 aresec.

Accurate resistivity and Hall effect measurements on thin, highly resistive layers are usually very difficult unless the layer is removed from its substrate. For these layers, the removal was accomplished by a technique developed for LT GaAs, which makes use of a 500-Å-thick AlAs layer underneath the layer of interest. ${ }^{6}$ The completed samples consisted of $6 \mathrm{~mm} \times 6 \mathrm{~mm}, 1-2-\mu \mathrm{m}$-thick InGaP layers mounted on similar sized pieces of microscope slide glass. Indium contacts were placed on the corners with a soldering iron and Hall effect measurements were carried out from $300-500 \mathrm{~K}$ in an automated apparatus designed for high-resistance samples.

Although all samples grown in the range $150-250^{\circ} \mathrm{C}$ showed high resistivity, when measured before substrate removal, only the samples grown at the representative temperature of $200^{\circ} \mathrm{C}$ were chosen for substrate removal because of the complexity of this process. The experimental room-temperature $(296 \mathrm{~K}$ ) values for resistivity $\rho$, mobility $\mu$, and electron concentration $n$ of the $200^{\circ} \mathrm{C}$, unannealed sample were $8.7 \times 10^{5} \Omega \mathrm{cm}, 120 \mathrm{~cm}^{2} / \mathrm{V} \mathrm{s}$, and 6.0 $\times 10^{10} \mathrm{~cm}^{-3}$, respectively. Other $200^{\circ} \mathrm{C}$ samples had very similar characteristics. The theoretical electron mobility was calculated ${ }^{7}$ by including all the important scattering mechanisms, including alloy scattering, in a numerical solution of the Boltzmann transport equation. ${ }^{8,9}$ Input parameters for the various scattering mechanisms were linearly interpolated from known values of the end-point (InP or GaP) parameters, or were estimated. ${ }^{8-10}$ Without

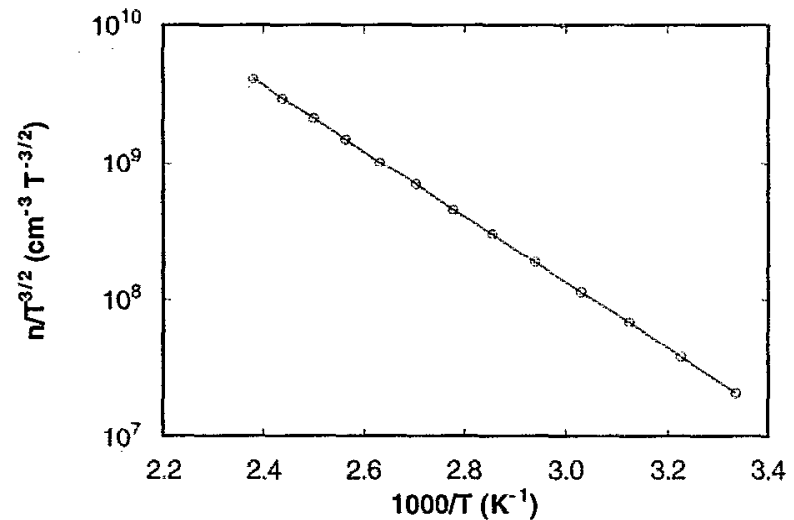

FIG. 3. A plot of $n / T^{3 / 2}$ vs $1000 / T$ for a $2-\mu \mathrm{m}$-thick InGaP layer grown at $200^{\circ} \mathrm{C}$ and separated from its $\mathrm{GaAs}$ substrate. The slope gives an activation energy of $0.48 \mathrm{eV}$.

ionized-defect scattering, the theoretical electron mobility for InGaP was $334 \mathrm{~cm}^{2} / \mathrm{V} \mathrm{s}$. To reduce this value to 120 $\mathrm{cm}^{2} / \mathrm{Vs}$ required an ionized-defect concentration of $9 \times 10^{17} \mathrm{~cm}^{-3}$. Experimental mobilities for relatively pure $n$-type HT InGaP are as high as $1000 \mathrm{~cm}^{2} / \mathrm{V} \mathrm{s}$, suggesting that some of our theoretical input parameters were incorrect. However, using 1000 instead of $334 \mathrm{~cm}^{2} / \mathrm{V} \mathrm{s}$ as the lattice-limited mobility changed the required ionizeddefect concentration only to $1.2 \times 10^{18} \mathrm{~cm}^{-3}$. This concentration must be considered only a rough estimate at present, but does suggest a very large defect density in LT In GaP as is also present in LT GaAs. However, in contrast to the LT GaAs case, ${ }^{11}$ the density in LT InGaP is not large enough to produce a hopping conduction between donors; that is why the material remains semi-insulating. The theoretical mobility was nearly temperature independent, decreasing about $3 \%$ from $300-420 \mathrm{~K}$, while the experimental mobility actually increased slightly, about $8 \%$, over this same temperature range.

Further information on the dominant donor can be found from an Arrhenius plot, $n / T^{3 / 2}$ vs $T^{-1}$, displayed in Fig. 3. The activation energy determined from such a plot is $0.48 \pm 0.01 \mathrm{eV}$, which means that the defect involved has a $T=0$ transition at $E_{C}-0.48 \mathrm{eV}$. From the knowledge that most of the LT III-V materials grown so far are anion rich, a good candidate for the donor would be a $\mathbf{P}$ antisite. One recent theory ${ }^{12}$ suggests $(0 /+) P$ antisite transitions at $E_{V}+0.44 \mathrm{eV}$ in InP and $E_{V}+1.83 \mathrm{eV}$ in GaP, so that for InGaP a transition near $E_{V}+1.13 \mathrm{eV}$ (or $E_{C}-0.76 \mathrm{eV}$ ) might be expected. The observed activation energy, $E_{C}$ $-0.48 \mathrm{eV}$, is within error of the theoretical value, but no firm conclusions regarding the defect identity can be drawn at this time.

Annealing the LT InGaP at $600^{\circ} \mathrm{C}$ for $1 \mathrm{~h}$ produces a material with even higher resistivity, impossible to measure at $296 \mathrm{~K}$ but extrapolated from higher temperature measurements $(360-500 \mathrm{~K})$ to be about $4 \times 10^{9} \Omega \mathrm{cm}$ at 296 K. No Hall coefficient could be measured in this temperature range, but the resistivity had an activation energy of $0.8 \mathrm{eV}$. This material could be useful as a gate insulator in a MISFET application. 
Preliminary attempts were made to observe thermally stimulated current (TSC) peaks in order to study the deep levels. ${ }^{13}$ However, no TSC signals could be seen, which is probably due to a very short carrier lifetime. To further investigate the carrier lifetime, the photocurrent (PC) was measured. In a strong white light $\left(\sim 10^{16}\right.$ photons $\left./ \mathrm{cm}^{2} \mathrm{~s}\right)$, and with a $10 \mathrm{~V}$ bias across the sample, the $\mathrm{PC}$ was $0.5 \mathrm{pA}$ at $200 \mathrm{~K}$, which suggests a lifetime of perhaps $1-10$ ps.

In summary, we have grown InGaP at $200^{\circ} \mathrm{C}$ and shown that it is semi-insulating, with a resistivity of about $10^{6} \Omega \mathrm{cm}$, and a mobility of $120 \mathrm{~cm}^{2} / \mathrm{V} \mathrm{s}$. The Fermi level is controlled by a deep donor at $0.48 \mathrm{eV}$, possibly a $P$ antisite. The material has many of the same properties as those in LT GaAs, including a very short carrier lifetime; however, a difference is that no hopping conduction is found in as-grown InGaP, so that this material does not require an anneal to be semi-insulating.

We wish to thank G. D. Robinson for separating the layer from its substrate, T. A. Cooper for electrical measurements, J. R. Sizelove for transport calculations and $\mathrm{N}$. Blair for manuscript preparation. D.C.L was supported under USAF Contract F33615-91-C-1765 and all of his work was carried out at the Solid State Electronics Directorate, Wright Laboratory, Wright-Patterson Air Force
Base, OH. The work at North Carolina State University was supported under a University Research Initiative (URI) grant.

' $\mathrm{K}$. H. Bachem, Th. Lauterbach, M. Maier, W. Pletschen, and K. Winkler, Inst. Phys. Conf. Ser. 120, 293 (1991).

${ }^{2} \mathrm{~B}$. Clerjaud, in Semi-Insulating III-V Materials, Malmo, 1988, edited by G. Grossman and L. Ledebo (IOP, Bristol, 1988), p. 303.

${ }^{3}$ C. R. Wie, K. Xie, D. C. Look, K. R. Evans, and C. E. Stutz, in Semi-Insulating III-V Materials, Toronto, 1990, edited by A. Milnes and C. J. Miner (IOP, Bristol, 1990), p. 71.

${ }^{4} \mathrm{~J}$. Ramdani, Y. He, M. Leonard, N. El-Masry, and S. M. Bedair, Appl. Phys. Lett. 61, 1646 (1992)

${ }^{5}$ Y. He, J. Ramdani, N. El-Masry, S. M. Bedair, and D. C. Look, J. Electron. Mater. (to be published).

${ }^{6}$ D. C. Look, G. D. Robinson, J. R. Sizelove, and C. E. Stutz, in SemiInsulating III-V Materials, Ixtapa, 1992, edited by C. J. Miner, W. Ford, and E. R. Weber (IOP, Bristol, 1993).

${ }^{7}$ D. C. Look and J. R. Sizelove (unpublished).

${ }^{8}$ B. R. Nag, Electron Transport in Compound Semiconductors (Springer, Berlin, 1980)

${ }^{9}$ D. L. Rode, in Semiconductors and Semimetals, edited by $\mathbf{R}$. K. Willardson and A. C. Beer (Academic, New York, 1975), Vol. 10, p. 1.

${ }^{10}$ Semiconductors: Group IV Elements and Group III-V Elements, edited by $O$. Madelung (Springer, Berlin, 1991).

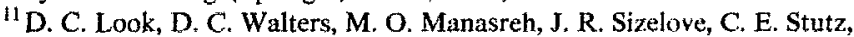
and K. R. Evans, Phys. Rev. B 42, 3578 (1990).

${ }^{12}$ M. J. Puska, J. Phys. Condens. Matter 1, 7347 (1989).

${ }^{13}$ Z.-Q. Fang and D. C. Look (unpublished). 